\title{
Understanding the Revival of the Indian Summer Monsoon after Breaks $\mathscr{A}$
}

\author{
DANDU GOVARDHAN \\ University Centre for Earth and Space Sciences, University of Hyderabad, Hyderabad, India \\ VADLAMUDI BRAHMANANDA RAO \\ National Institute for Space Research, São Paulo, Brazil \\ KARUMURI ASHOK \\ University Centre for Earth and Space Sciences, University of Hyderabad, Hyderabad, India
}

(Manuscript received 19 November 2016, in final form 1 February 2017)

\begin{abstract}
In this paper, the authors suggest a dynamical mechanism involved in the revival of the summer monsoon after breaks. In this context, the authors carry out a diagnostic analysis using the datasets from National Centers for Environmental Prediction Reanalysis 2 for the period 1979-2007 to identify a robust mechanism that typifies breaks and subsequent revival of monsoon. The authors find during the peak of significant breaks an anomalous southward shift of the subtropical westerly jet stream, which is invariably accompanied by an anomalous northward shift of a stronger-than-normal easterly jet. These major changes during a break facilitate an instability mechanism, which apparently leads to formation of a synoptic disturbance. Formation of such a disturbance is critical to the subsequent revival of the summer monsoon in $61 \%$ of the observed breakto-active revivals.

Computations of energetics and correlation analysis carried out suggest an increase in the eddy kinetic energy at the expense of the mean kinetic energy during the breaks, in agreement with the formation of the synoptic disturbance. This demonstrates that barotropic instability in the presence of a monsoon basic flow is the primary physical mechanism that controls the revival of the summer monsoon subsequent to the break events.
\end{abstract}

\section{Introduction}

The spatial and temporal variability of precipitation during the Indian summer monsoon (ISM) is very important for the Indian economy, which is mainly based on agriculture. The ISM experiences, in addition to the dominant interannual variability, intraseasonal variability in the form of active and break spells of rainfall. Blanford (1886), in a pioneering work suggested the "intervals of drought" as the break periods during the peak monsoon months of July-August. Also, recent studies suggest that droughts are associated with longer

Supplemental information related to this paper is available at the Journals Online website: http://dx.doi.org/10.1175/ JAS-D-16-0325.s1.

Corresponding author e-mail: Karumuri Ashok, ashokkarumuri@ uohyd.ac.in breaks (Joseph et al. 2009; Raman and Rao 1981). Typically, during the monsoon breaks, the monsoon trough in the sea level pressure, normally extending from the head of the Bay of Bengal northwestward into Gujarat and adjoining Pakistan, is seen to propagate farther north into the foothills of Himalayas. This results in anomalously surplus rainfall in the Himalayan regions and below-normal rainfall to the south (Ramamurthy 1969; Krishnamurti and Ardanuy 1980; Krishnan et al. 2000, 2009; Rajeevan et al. 2008, 2010). The active condition of the ISM, on the other hand, is when the sea level pressure trough moves south of its normal position, resulting in above-normal rainfall along the climatological monsoon trough regions and in many parts of the peninsula (Sikka and Narsimha 1995; Rao 1976; Alexander et al. 1978; Das 2002; Rajeevan et al. 2010; Choudhury and Krishnan 2011). Compared with other scales, intraseasonal variability of the ISM represents a higher amplitude of the seasonal mean (Goswami 2011; 
TABLE 1. A complete list of the symbols/notations representing various variables/parameters in the study.

\begin{tabular}{cl}
\hline \hline Symbol & \multicolumn{1}{c}{ Definition } \\
\hline$U$ & Zonal wind \\
$V$ & Meridional wind \\
$D / 2$ & Latitudinal distance \\
$L_{c}$ & Critical wavelength \\
$\bar{K}$ & Mean kinetic energy \\
$K^{\prime}$ & Eddy kinetic energy \\
$\zeta$ & Absolute vorticity \\
$f$ & Coriolis force \\
$m$ & Mass \\
$u^{\prime}$ & Eddy zonal wind \\
$v^{\prime}$ & Eddy meridional wind \\
\hline
\end{tabular}

Waliser 2006). Goswami et al. (2003) suggest that the emphasis of meridional shear of zonal winds and cyclonic vorticity along the monsoon trough results in increased (decreased) frequency of occurrence of low pressure systems during active (break) phase by the intraseasonal oscillations. The intraseasonal variability of ISM manifests as two broad peaks of variability, namely 10-20- and 30-60-day variabilities, with active and break phases that are linked to the northward migration of monsoon trough/ridge (Pai et al. 2009; Krishnamurti and Subrahmanyam 1982; Joseph and Sijikumar 2004; Krishnamurthy and Shukla 2007).

The revival of active conditions during the ISM is facilitated by the formation of synoptic disturbances in the Bay of Bengal, monsoon depressions, and low pressure systems that travel toward the northwest from Bay of Bengal into the Indian region (Chen et al. 2005; Sikka and Dixit 1972; Boos et al. 2015; Sikka and Gadgil 1980), many times along the monsoon trough, and cause copious rainfall. Krishnamurthy and Ajayamohan (2010) have shown that the absence of low pressure systems, such as lows, depressions, and cyclonic storms, represents the break phase and their presence represents an active phase of ISM.

From a dynamical perspective, some pioneering papers by Ramaswamy $(1956,1962)$ highlight the importance of anomalous southward shift of large-amplitude westerly troughs from the midlatitudes into the IndoPakistan region during breaks in the ISM. Importantly, further analyzing a case study studied by Ramaswamy (1962), Rao (1971) documents a manifestation of barotropic instability associated with increased horizontal shear due to the southward shift of the westerly troughs in the subtropical westerly jet at the midtropospheric level in the aforementioned break event and a subsequent revival associated with the formation of a synoptic disturbance. Rao (1971) hypothesized
TABLE 2. The formation of a synoptic disturbance on the particular day after every break event during the 1979-2007 period. An asterisk represents the revival of ISM without low formation.

\begin{tabular}{|c|c|c|}
\hline Year & $\begin{array}{c}\text { Low formation day after } \\
\text { every break event }\end{array}$ & Condition \\
\hline 1979 & - & * \\
\hline 1979 & - & $*$ \\
\hline 1980 & $23 \mathrm{Jul}$ & Bay of Bengal \\
\hline 1980 & 26 Aug & Bay of Bengal \\
\hline 1981 & - & $*$ \\
\hline 1982 & $19 \mathrm{Jul}$ & Bay of Bengal \\
\hline 1983 & 4 Aug & Bay of Bengal \\
\hline 1984 & $30 \mathrm{Jul}$ & Bay of Bengal \\
\hline 1985 & 28 Aug & Bay of Bengal \\
\hline 1986 & 9 Sep & Bay of Bengal \\
\hline 1987 & 11 Aug & Land region \\
\hline 1987 & 19 Aug & Bay of Bengal \\
\hline 1988 & - & $*$ \\
\hline 1989 & $2 \mathrm{Aug}$ & Bay of Bengal \\
\hline 1989 & 16 Aug & Bay of Bengal \\
\hline 1992 & $18 \mathrm{Jul}$ & Land region \\
\hline 1993 & - & $*$ \\
\hline 1993 & - & $*$ \\
\hline 1993 & $6 \mathrm{Sep}$ & Bay of Bengal \\
\hline 1995 & - & $*$ \\
\hline 1995 & - & $*$ \\
\hline 1996 & & $* * *$ \\
\hline 1997 & $22 \mathrm{Jul}$ & Bay of Bengal \\
\hline 1997 & 16 Aug & Bay of Bengal \\
\hline 1998 & 1 Sep & Land region \\
\hline 1998 & $29 \mathrm{Jul}$ & Land region \\
\hline 1999 & - & $*$ \\
\hline 1999 & - & $*$ \\
\hline 1999 & - & $*$ \\
\hline 2000 & $10 \mathrm{Aug}$ & Bay of Bengal \\
\hline 2001 & $6 \mathrm{Aug}$ & Bay of Bengal \\
\hline 2001 & 11 Sep & Land region \\
\hline 2002 & - & $*$ \\
\hline 2002 & $1 \mathrm{Aug}$ & Bay of Bengal \\
\hline 2004 & - & $*$ \\
\hline 2004 & $26 \mathrm{Jul}$ & Land region \\
\hline 2004 & - & $*$ \\
\hline 2005 & 11 Sep & Bay of Bengal \\
\hline 2005 & 19 Aug & Land region \\
\hline 2007 & - & $*$ \\
\hline 2007 & 18 Aug & Bay of Bengal \\
\hline
\end{tabular}

that manifestation of the barotropic instability during break leads to the formation of disturbances that in turn invigorate the ISM an active phase. Satyan et al. (1980) addressed the problem by using a twolayer quasigeostrophic model and carried out a stability analysis of the simulated monsoon zonal flow corresponding to break conditions. Satyan et al. (1980) also document the revival of the postbreak monsoon through formation of a synoptic disturbance. Further, while the upper-level flow in the simulations of Satyan et al. (1980) is found to be stable during the 


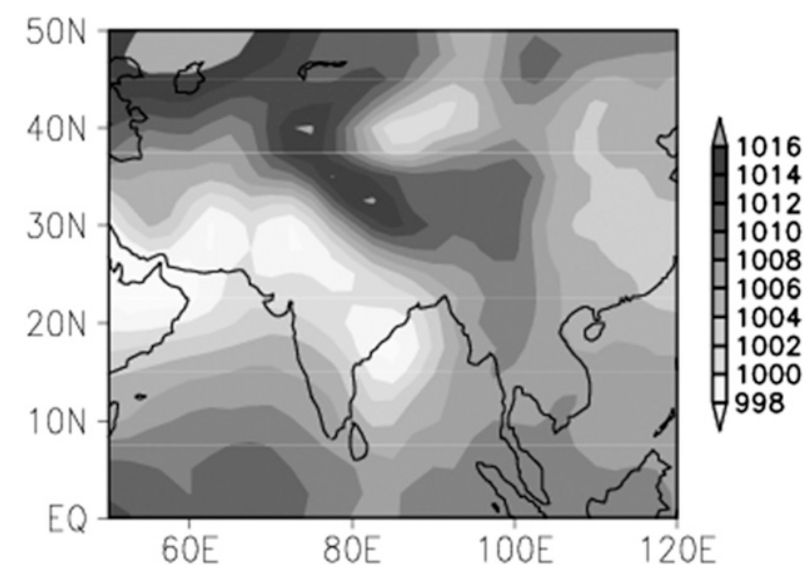

FIG. 1. Observed SLP distribution (hPa) on 10 Aug 2000, after a break period.

monsoon break conditions, it was found to be unstable a day before the formation of depression, supporting the argument of Rao (1971).

In the next few sentences, we briefly discuss some of the possible mechanisms such as the barotropic, baroclinic instabilities and other combined mechanisms, which have been suggested to explain the growth of the synoptic disturbances. The combined barotropic-baroclinic wind field study of the monsoon by Shukla (1977), using a 10-layered quasigeostrophic model, found that the barotropic mode is the only source for the upper-tropospheric growing mode at $150 \mathrm{hPa}$. Shukla (1978) numerically integrated the linearized perturbation equations for a three-layer quasigeostrophic model and performed a combined conditional instability of the second kind (CISK)barotropic-baroclinic instability analysis, which shows the maximum growth rate occurs for the smallest scales. On the other hand, Goswami et al. (1980), while suggesting that a large meridional shear of the eastward component of winds at the $200-\mathrm{hPa}$ level and a high cyclonic vorticity at low levels over the monsoon trough region during break periods favor growth of barotropic and baroclinic instabilities, adds that these instabilities cannot explain the initial growth for monsoon depressions. Therefore, the question remains whether instabilities generated by largescale processes lead to subsequent revival of the monsoon through a barotropic instability mechanism and formation of a synoptic disturbance. In this paper, we attempt to answer this question. The availability of reanalysis datasets in the recent decades is a great opportunity in this sense. Analysis of multiple cases will also help us to refine any theoretically based thresholds and indices that represent a
TABLE 3. Conversion of mean kinetic energy values $\left(\mathrm{J} \mathrm{s}^{-1}\right)$ at $200 \mathrm{hPa}$.

\begin{tabular}{|c|c|c|c|}
\hline Year & $\begin{array}{c}\text { Before break } \\
\text { period }\end{array}$ & $\begin{array}{c}\text { During break } \\
\text { period }\end{array}$ & $\begin{array}{c}\text { After break } \\
\text { period }\end{array}$ \\
\hline 1979 & -533.85 & -324.67 & 568.11 \\
\hline 1979 & -307.49 & -1668.31 & -1040.26 \\
\hline 1980 & -902.14 & 419.32 & -483.19 \\
\hline 1980 & -168.76 & 838.84 & 1241.05 \\
\hline 1981 & -445.01 & 41.06 & 654.83 \\
\hline 1982 & -206.31 & -104.81 & -873.12 \\
\hline 1983 & -483.50 & 932.99 & 345.91 \\
\hline 1984 & -381.30 & 386.58 & -334.05 \\
\hline 1985 & -691.33 & 1736.20 & 864.34 \\
\hline 1986 & -391.23 & 667.50 & 533.51 \\
\hline 1987 & -845.24 & -15.09 & 1909.51 \\
\hline 1987 & -845.24 & 266.40 & -92.27 \\
\hline 1988 & -267.84 & -600.93 & 884.11 \\
\hline 1989 & -134.70 & 1450.52 & 1326.88 \\
\hline 1989 & -272.84 & 722.94 & -289.01 \\
\hline 1992 & -209.65 & 551.18 & 796.84 \\
\hline 1993 & -662.03 & 641.99 & 500.70 \\
\hline 1993 & -27.15 & -134.37 & 132.38 \\
\hline 1993 & -154.66 & 171.96 & 1059.52 \\
\hline 1995 & -645.48 & 627.13 & -336.83 \\
\hline 1995 & -155.81 & 1094.81 & -499.51 \\
\hline 1996 & -410.98 & 1179.61 & 18.84 \\
\hline 1997 & -348.92 & -435.35 & -1599.46 \\
\hline 1997 & -424.11 & -249.73 & 147.87 \\
\hline 1998 & -111.57 & 296.10 & 1457.89 \\
\hline 1998 & -496.43 & 597.56 & -211.52 \\
\hline 1999 & -409.16 & -320.18 & 178.70 \\
\hline 1999 & -671.99 & 1026.46 & 727.02 \\
\hline 1999 & -691.03 & 1662.09 & 646.58 \\
\hline 2000 & -51.00 & 447.82 & -588.90 \\
\hline 2001 & -547.99 & -1176.18 & -147.23 \\
\hline 2001 & -348.58 & 224.42 & -108.66 \\
\hline 2002 & -1218.62 & 357.86 & -950.32 \\
\hline 2002 & -1218.62 & 818.58 & -950.32 \\
\hline 2004 & -309.27 & 1192.99 & -520.30 \\
\hline 2004 & -309.27 & 558.93 & -520.30 \\
\hline 2004 & -442.18 & 462.54 & 952.01 \\
\hline 2005 & -88.06 & 188.81 & 754.90 \\
\hline 2005 & -418.94 & -341.93 & -275.85 \\
\hline 2007 & -763.64 & 693.70 & 231.90 \\
\hline 2007 & -384.59 & 1507.19 & 1175.04 \\
\hline
\end{tabular}

phenomenon. For example, theory (Kuo 1953; Starr and White 1954; Aihara 1959) suggests that barotropic instability occurs only in disturbances of very long wavelengths. The case study of a break monsoon Rao (1971) suggests that synoptic waves in the subtropical westerly jet in the Indian region with a wavelength greater than (less than) $3000 \mathrm{~km}$ are unstable (stable). We revisit this aspect in this study. The details of the datasets used and methods of analysis are described in the next section. We present our results and a discussion in section 3 , followed by conclusions in section 4 . 


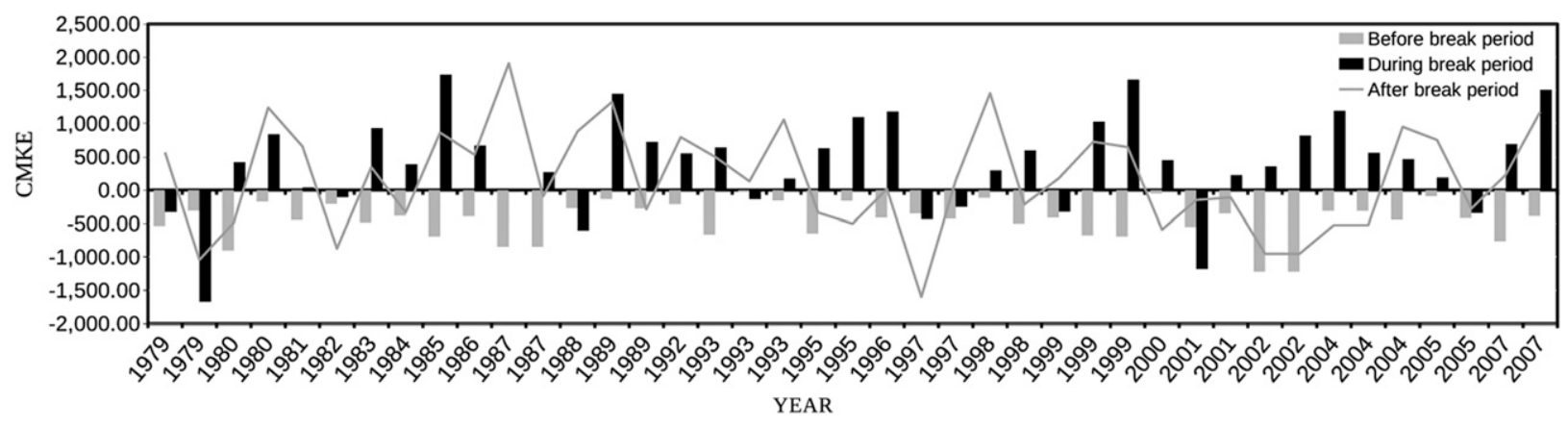

FIG. 2. Conversion of kinetic energy anomaly values $\left(\mathrm{J} \mathrm{s}^{-1}\right)$ for the 1979-2007 period.

\section{Data and methods}

\section{a. Data}

For the present study, we have used monsoon break periods based on Rajeevan et al. (2006) of ISM for the period 1979-2007. Following Rajeevan et al. (2010), we choose the region bounded by $18.0^{\circ}-28.0^{\circ} \mathrm{N}, 65.0^{\circ}-$ $88.0^{\circ} \mathrm{E}$ as the core monsoon region; indeed, on an interannual scale, the area-averaged rainfall in this region is highly correlated at 0.91 with that of interannual variation of the Indian summer monsoon (Rajeevan et al. 2010). The daily data employed in the study are zonal $(U)$ wind at $200 \mathrm{hPa}$, meridional $(V)$ wind, geopotential height, and sea level pressure (SLP). All of these products were obtained from National Centers for Environmental Prediction (NCEP) Reanalysis 2 (Kanamitsu et al. 2002). These datasets have a spatial resolution of $2.5^{\circ}$ latitude $\times 2.5^{\circ}$ longitude on a global grid and a temporal coverage of four-times-daily values from 1 January 1979 to 31 December 2007. In addition, the dates of the synoptic disturbances and locations were collected from the India Meteorological Department (2012; Cyclone eAtlas) data. In addition, the
SLP data from the NCEP Reanalysis 2 data were used to reconfirm the dates of formation of the synoptic disturbances. We adopt the breaks and active event dates following Rajeevan et al. (2010).

\section{b. Method}

Following Kuo (1953), Syōno and Aihara (1957), and Rao (1971), an index for barotropic instability is defined as the meridional shear in the daily $200-\mathrm{hPa}$ zonal wind. Further, the critical wavelength (neutral wavelength) of a zonal wave at this level is computed as

$$
L_{c}=\frac{2 D}{\sqrt{3}},
$$

where $D / 2$ is the zonal width between subtropical westerly jet and tropical easterly jet. Indeed, waves longer than wavelength $L_{c}$ become unstable and shorter than $L_{c}$ are stable (Starr and White 1954; Aihara 1959). The rate of conversion of mean kinetic energy (CMKE) is obtained by

$$
C\left(\bar{K}, K^{\prime}\right)=\int U \frac{\partial}{\partial y} \overline{v^{\prime} u^{\prime}} d m
$$
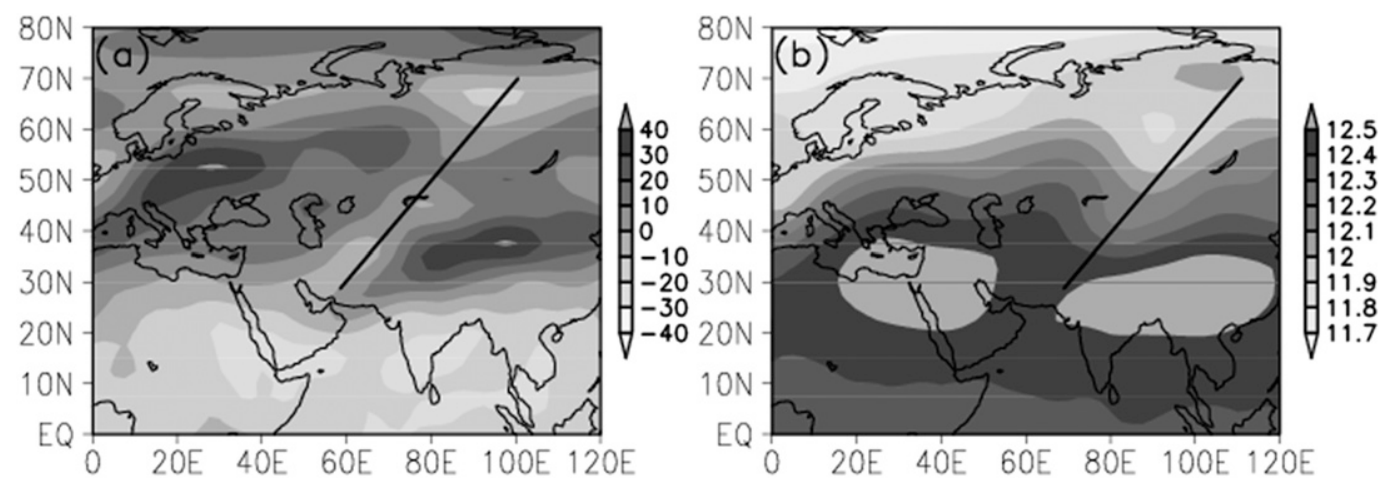

FIG. 3. (a) Zonal wind $\left(\mathrm{m} \mathrm{s}^{-1}\right)$ at $200 \mathrm{hPa}$ on $4 \mathrm{Aug} 2000$, a typical break day. (b) The corresponding geopotential distribution $(\mathrm{km})$. 

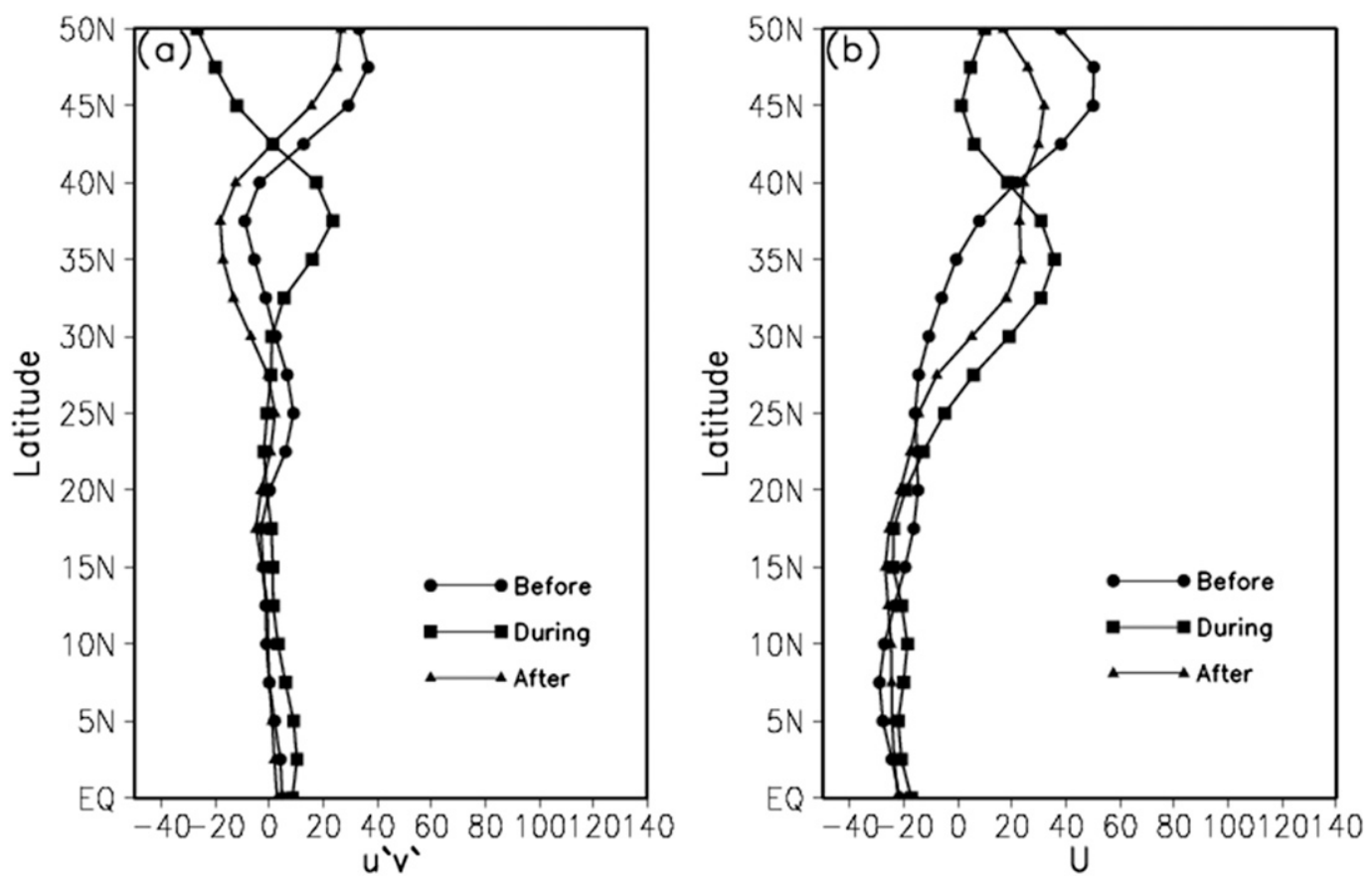

FIG. 4. (a) Eddy momentum flux transfer $\left(\mathrm{m}^{2} \mathrm{~s}^{-2}\right)$, which is averaged zonally, during a break (1-9 Aug), before the break (14-23 Jul), and after the break (10-15 Aug), relative to the 1-9 Aug break in the year 2000. (b) Zonal wind profiles $\left(\mathrm{m} \mathrm{s}^{-1}\right)$ at $82.5^{\circ} \mathrm{E}$ and $200 \mathrm{hPa}$ during a break day (4 Aug), on a day in the prebreak period (23 Jul), and on a postbreak day (11 Aug), all for the event presented in (a).

where $\mathrm{m}$ is the mass, $\bar{K}$ is the mean kinetic energy $\left(\mathrm{J} \mathrm{s}^{-1}\right), K^{\prime}$ is the eddy kinetic energy, $U$ is the zonal wind $\left(\mathrm{m} \mathrm{s}^{-1}\right)$, and $V$ is the meridional wind $\left(\mathrm{m} \mathrm{s}^{-1}\right)$. A complete list of the symbols/notations representing various variables/parameters in this study is provided in Table 1. The $u^{\prime}$ and $v^{\prime}$ have been obtained as the daily anomalies from the zonal mean of the respective circulation component averaged over $20^{\circ}-120^{\circ} \mathrm{E}$. Equation (2) means that if there is divergence (convergence) of eddy momentum transport in region of westerlies, $\bar{K}$ gets converted into $K^{\prime}\left(K^{\prime}\right.$ gets converted into $\left.\bar{K}\right)$; that is, the disturbance is barotropically unstable (stable). In our analysis, we use the criterion by Kuo (1951), which states that, for barotropic instability to happen at a location, the meridional gradient of the absolute vorticity has to be either maximum or minimum. The corresponding mathematical expression is shown in (3):

$$
\frac{d \zeta}{d y}=0
$$

As per Kuo (1951) the above expression for the largely zonal flow can be approximated as

$$
\frac{d}{d y}\left(\frac{-d \bar{U}}{d y}+f\right)=0
$$

where $\bar{U}$ is the mean zonal wind, $f$ is the Coriolis force, and $\zeta$ is the absolute vorticity. We use the criterion shown in (3) to explain the mechanism behind the formation of the postbreak synoptic disturbances over the Indian region and the Bay of Bengal, which reactivate the Indian summer monsoon.

\section{Results and discussion}

\section{a. Barotropic instability in the aftermath of breaks}

From the works of Starr and White (1954) and Rao (1971), we can suppose that such a break condition will result in barotropic instability, which may in turn manifest as a synoptic disturbance for the revival of ISM. In this context, from Table 1, following Rajeevan et al. (2008), we list the dates of various postbreak revival events of ISM. Of the 41 total events (Table 2), 18 revivals occurred with the formation of low pressure in the Bay of Bengal (e.g., Fig. 1) and 7 others with the formation of low pressure on land (figures not shown). This result suggests that about $61 \%$ of the postbreak revivals are associated with formation of low pressure in the Bay of Bengal or land regions, providing a general support to the hypothesis of Rao (1971) and Raghavan (1973). 

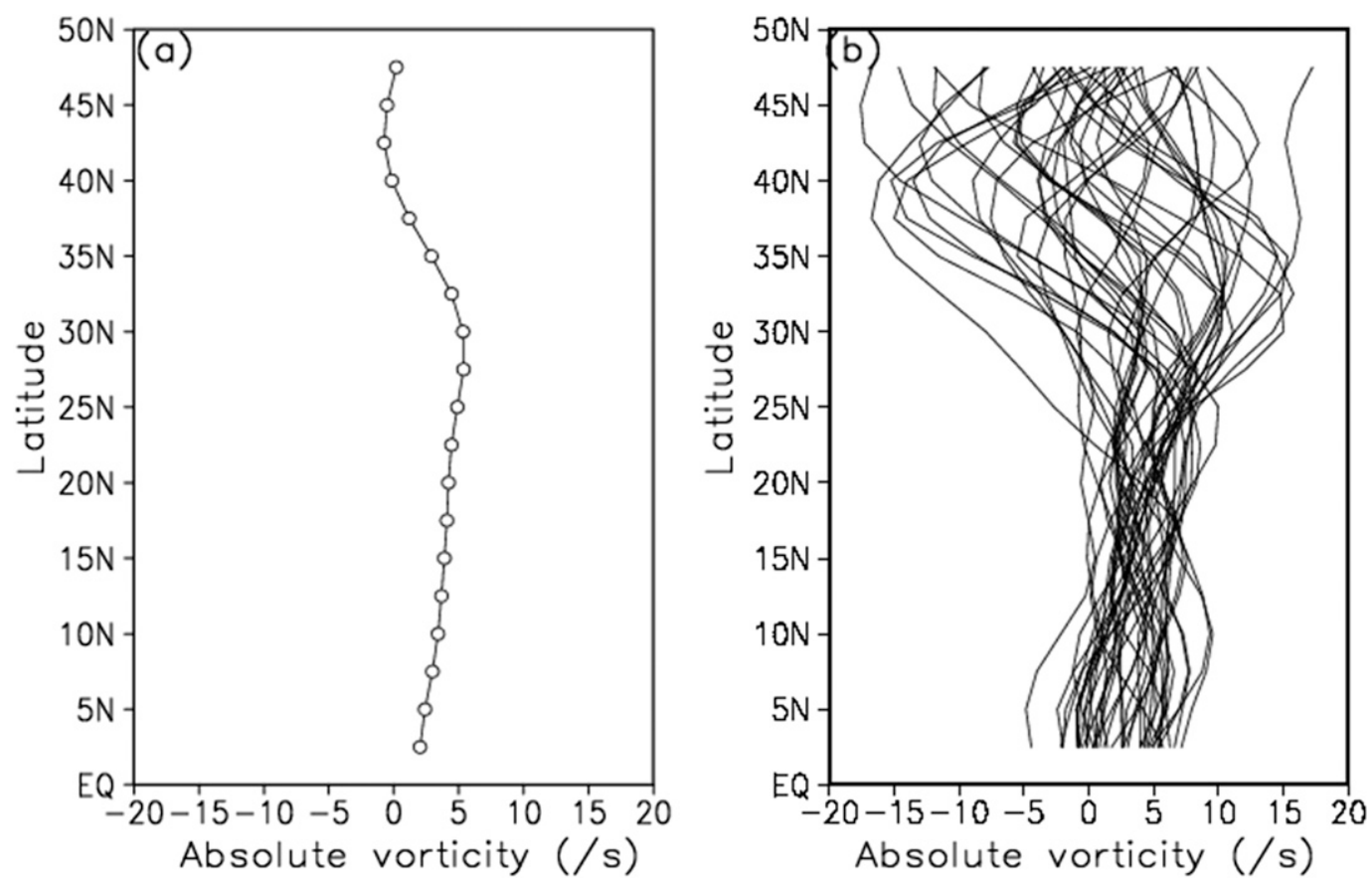

FIG. 5. (a) Meridional distribution of the composite absolute vorticity $\left(\mathrm{s}^{-1}\right)$ at $200 \mathrm{hPa}$, obtained by compositing it over all the break periods during 1979-2007. (b) As in (a), but composited over each break period during 1979-2007.

Now, eddy formation due to barotropic instability would necessitate a conversion of the $\bar{K}$ into $K^{\prime}$, as shown by (2). Indeed, this is true in 30 out of the 41 cases (i.e., $73 \%$ of postbreak revival events), as evidenced by the positive values of CMKE (Table 3) (Fig. 2). This indicates that the barotropic instability is the primary possible large-scale dynamical instability mechanism during the ISM breaks, many times leading to the formation of synoptic eddies. Another way to ascertain this further is by checking that there exists a significant negative correlation between the CMKE and wavelength, an indication of barotropic instability (e.g., Rao 1971). We find a strong correlation of -0.285 (Table 2), which is significant at $95 \%$ confidence level from a Student's twotailed $t$ test. This significant correlation confirms that barotropic instability is indeed manifested after the monsoon break events and is a necessary condition for the revival of Indian summer monsoon after break conditions.

What is the potential mechanism for such manifestation of barotropic instability in these subseasonal events? As is known, barotropic disturbances derive energy from the mean kinetic energy. Energy considerations (e.g., Kuo 1951) show that for a disturbance to grow, it must tilt in a direction opposite to that of the meridional gradient of zonal wind. To be specific, a tilt from southwest to northeast (SW-NE) in a westerly zonal flow will meet this criterion. That is, waves with an SW-NE tilt will result in a maximum vorticity to the south [see (3), which is from Kuo (1949)]. From supplementary Figs. S1 and S2, it is seen most of the break days are also indeed associated with such an SW-NE tilt in the 200-hPa zonal flow. Such a tilt in the mean 200-hPa subtropical westerly jet over the Indian region on a typical break day (see Fig. 3a as an example, along with the corresponding geopotential field in Fig. 3b) is associated with a northward transfer of westerly momentum (Kuo 1949). In such a case, the zonally averaged eddy momentum transport $\left(\overline{u^{\prime} v^{\prime}}\right)$ will be positive and is, importantly, conducive to the formation of an eddy disturbance (Fig. 4a) associated with maximum vorticity to its south (Kuo 1949). Truly, the corresponding zonal wind structure at $200 \mathrm{hPa}$ shows a southward shift of the westerly jet during the break period and a northward shift of the tropical easterly jet (Fig. 4b).

From the point of Rao (1971), it will be instructive to verify that the barotropic instability is a mechanism that would help the aforementioned eddies grow in such situations. To that end, the meridional vorticity distribution of the absolute vorticity $\zeta$ in the Indian region during the break events is presented in Fig. 5a, along with the corresponding composite in 
Fig. 5b. Importantly, we see maximum or minimum in absolute vorticity $\zeta$ around $29^{\circ} \mathrm{N}$ in the composite, with the individual values varying between $25^{\circ}$ and $30^{\circ} \mathrm{N}$. Manifestation of such maximum or minimum values is a necessary condition for the barotropic instability (Kuo 1951) from the individual case also indicates such manifestation (Fig. 5b). All this highlights the importance of the mean seasonal zonal wind structure, with westerlies to the north and easterlies to the south of the Indian subcontinent, in facilitating such a dynamical instability manifested by the breaks.

\section{b. Wavelength threshold for manifestation of a postbreak synoptic disturbance}

Ramaswamy (1962) and Rao (1971) claim from their individual case studies a decrease in channel width $(D / 2)$ between subtropical westerly and tropical easterly jets that manifest as a dynamical instability. We revisit this aspect by computing the $D / 2$ during the break events in the study period. Our results (Table 4 and Fig. 6) show that 32 out of 41 break events $(78 \%)$ indeed show a decrease in channel width. From this, we can deduce that a dynamical instability during the breaks is facilitated either as a result of a transient southward shift of the westerlies over the northern portions of the subcontinent and/or a transient northward shift of the tropical easterly jet stream over the peninsular region. Such a decrease in the channel width in the zonal width can also manifest with a weakening (strengthening) of the upper-level westerlies (easterlies) in the Indian region.

Theory (Kuo 1953; Syōno and Aihara 1957) shows that barotropic instability occurs only in zonal waves of wavelength shorter than a critical wavelength $L_{c}$ [see (1)]. Rao (1971), from his sole case study, estimates $L_{c}$ of the upper-level westerly jet stream in the Indian region to be $\sim 3000 \mathrm{~km}$. However, given that it was only a single case and the relatively poor quality of the upper-air data during that period, we use the reanalyzed gridded datasets for multiple monsoon break cases to revisit this important finding by Rao (1971). Our analysis using (1) (Table 4) shows that (i) wavelengths in the upper-level westerlies north of Indian region during the summer monsoon reach a minimum value during breaks as compared to a few days prior to and after the event and (ii) the critical mean value of the aforementioned wavelength, obtained by averaging it over all break events, is $7411 \mathrm{~km}$. The minimum $L_{c}$ we find is just $5127 \mathrm{~km}$ (Fig. 7; also see Table 5).
TABLE 4 . The channel width $\left(D / 2 ;^{\circ}\right)$ between the subtropical westerly jet and tropical easterly jet at $200 \mathrm{hPa}$ during the 19792007 period.

\begin{tabular}{|c|c|c|c|}
\hline Year & $\begin{array}{l}\text { Before break } \\
\text { period }\end{array}$ & $\begin{array}{c}\text { During break } \\
\text { period }\end{array}$ & $\begin{array}{l}\text { After break } \\
\text { period }\end{array}$ \\
\hline 1979 & 35.43 & 28.25 & 26.11 \\
\hline 1979 & 31.00 & 30.00 & 34.50 \\
\hline 1980 & 42.25 & 37.25 & 34.83 \\
\hline 1980 & 28.88 & 23.67 & 31.83 \\
\hline 1981 & 35.00 & 31.75 & 34.29 \\
\hline 1982 & 29.88 & 25.63 & 34.43 \\
\hline 1983 & 33.29 & 35.33 & 36.38 \\
\hline 1984 & 30.63 & 22.67 & 43.00 \\
\hline 1985 & 31.00 & 20.00 & 36.14 \\
\hline 1986 & 33.57 & 26.00 & 26.25 \\
\hline 1987 & 26.10 & 29.83 & 22.67 \\
\hline 1987 & 32.14 & 29.33 & 39.14 \\
\hline 1988 & 38.00 & 32.75 & 30.83 \\
\hline 1989 & 26.43 & 28.00 & 43.29 \\
\hline 1989 & 48.86 & 40.20 & 44.00 \\
\hline 1992 & 31.22 & 28.88 & 39.63 \\
\hline 1993 & 30.43 & 25.75 & 42.43 \\
\hline 1993 & 33.86 & 22.29 & 31.43 \\
\hline 1993 & 30.14 & 28.57 & 38.43 \\
\hline 1995 & 34.57 & 26.80 & 37.71 \\
\hline 1995 & 35.29 & 28.67 & 37.83 \\
\hline 1996 & 37.38 & 39.00 & 37.83 \\
\hline 1997 & 41.71 & 39.20 & 34.29 \\
\hline 1997 & 34.43 & 30.83 & 41.00 \\
\hline 1998 & 29.00 & 23.00 & 30.67 \\
\hline 1998 & 24.29 & 23.14 & 35.43 \\
\hline 1999 & 24.43 & 25.80 & 26.14 \\
\hline 1999 & 39.57 & 35.80 & 25.86 \\
\hline 1999 & 31.43 & 20.50 & 39.43 \\
\hline 2000 & 34.63 & 28.89 & 37.33 \\
\hline 2001 & 25.43 & 26.33 & 37.43 \\
\hline 2001 & 34.00 & 29.40 & 29.57 \\
\hline 2002 & 29.86 & 31.43 & 38.86 \\
\hline 2002 & 29.86 & 30.82 & 38.86 \\
\hline 2004 & 28.13 & 32.25 & 40.20 \\
\hline 2004 & 28.13 & 23.67 & 40.2 \\
\hline 2004 & 29.70 & 23.33 & 31.00 \\
\hline 2005 & 31.86 & 24.25 & 38.63 \\
\hline 2005 & 32.71 & 33.63 & 34.86 \\
\hline 2007 & 25.38 & 25.20 & 29.43 \\
\hline 2007 & 37.57 & 37.00 & 40.57 \\
\hline
\end{tabular}

\section{Conclusions}

Ramaswamy (1962) and Rao (1971) show, through individual case studies that transition from break to active conditions occurs during the Indian summer monsoon (ISM) owing to the manifestation of barotropic instability, which leads to formation of a synoptic disturbance. Given the critical importance of break-active cycles in defining the seasonal rainfall envelope (Goswami et al. 2003; Goswami and Ajayamohan 2001) during the ISM, it is very important to revisit the conclusions of these case studies. With 


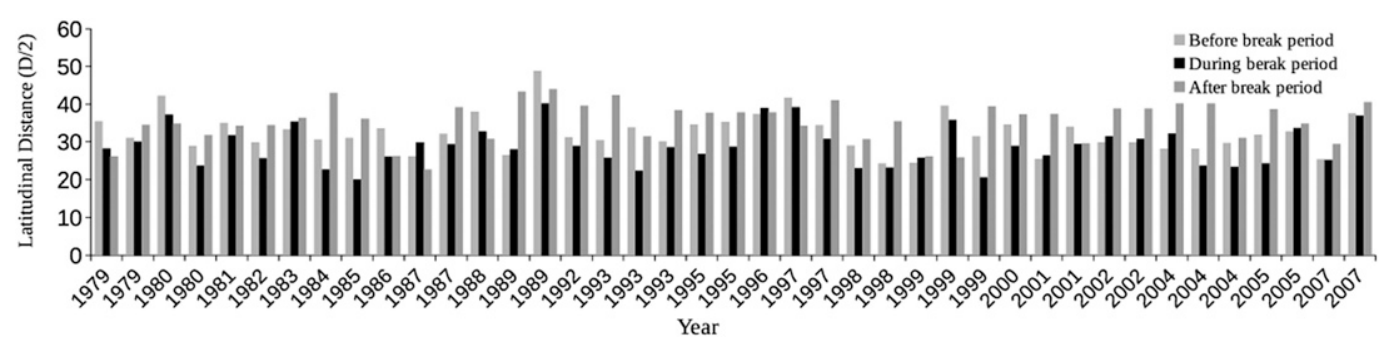

FIG. 6. Latitudinal distance $\left(^{\circ}\right)$ between westerlies and easterlies at $200 \mathrm{hPa}$ for various phases associated with observed break events.

this goal in mind, using the atmospheric circulation datasets from the NCEP-NCAR Reanalysis 2 (Kanamitsu et al. 2002) for the period 1979-2007, we explore the potential role of monsoon break conditions in subsequent revival of the monsoon through formation of a synoptic disturbance in the Indian region. We adopt the monsoon active and break calendar documented by Rajeevan et al. (2008). We find that barotropic instability manifests in the Indian region during monsoon breaks in $61 \%$ of the cases. Such a revival is found to be associated with a reduction of the "zonal width" between the upper-level subtropical westerlies and tropical easterlies. Our correlation analysis between the wavelength of zonal winds in the Indian region and the rate of conversion of mean kinetic energy values for the study period is -0.285 , statistically significant at $95 \%$ confidence level, which confirms the role of barotropic instability for formation of the postbreak synoptic disturbance (e.g., Aihara 1959). During the monsoon break period there is no rainfall over most of the country, and therefore the succeeding disturbances are not generated by the condensational heating. Thus, the argument that generation of monsoon depressions and synoptic disturbances due to the break-induced barotropic instability is reasonable. We also find that the mean wavelength of westerlies during boreal monsoon events north of the Indian region, which leads to the revival of the monsoons, is about $7400 \mathrm{~km}$. While Rao (1971) suggests a threshold wavelength of $3000 \mathrm{~km}$ from his study, our analysis of the 41 cases suggests an apparent threshold from our sample to be above $5000 \mathrm{~km}$.

As this study has been mainly carried out using the NCEP-NCAR Reanalysis 2 (Kanamitsu et al. 2002), in the future, we plan to explore these issues in other reanalysis datasets and various available mediumrange hindcast runs (e.g., Mitra 2003a,b, 2009, 2013) and by conducting a few numerical sensitivity experiments.

We also need to remember that the Indian summer monsoon variability is controlled by several factors and drivers. In addition, formation of a disturbance depends on various other factors such as SST and moisture availability. The monsoon can also revive as a result of largescale circulation changes, in which case the manifested instability may be different. From this context, the relevance of the other mechanisms, such as the baroclinic instability, in the remaining cases of the break-active transitions that happen without the formation of a synoptic disturbance needs further examination.

Acknowledgments. The authors gratefully acknowledge the India Meteorological Department (IMD), India, for the cyclone/synoptic disturbance chronology (eAtlas) data from www.rmcchennaieatlas.tn.nic.in, and the NOAA-Earth

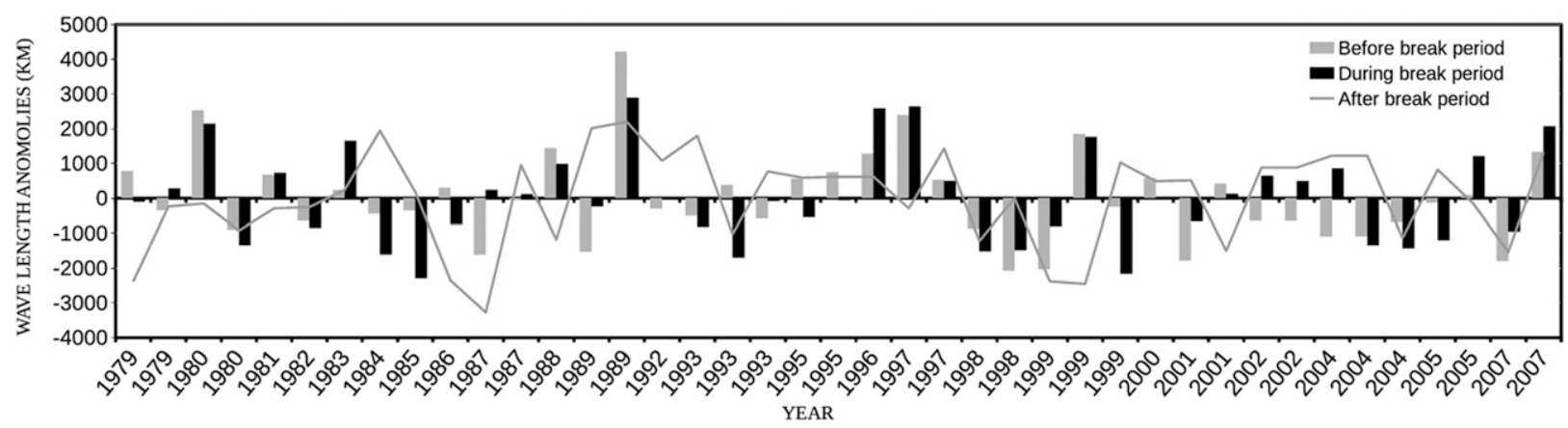

FIG. 7. Wavelength anomalies $(\mathrm{km})$ of the zonal wind at $200 \mathrm{hPa}$, averaged over the span of each break event. 
TABLE 5. Calculated values of wavelength $\left(L_{c} ; \mathrm{km}\right)$ before, during, and after break periods.

\begin{tabular}{|c|c|c|c|}
\hline Year & $\begin{array}{l}\text { Before break } \\
\text { period }\end{array}$ & $\begin{array}{c}\text { During break } \\
\text { period }\end{array}$ & $\begin{array}{c}\text { After break } \\
\text { period }\end{array}$ \\
\hline 1979 & 9082 & 7310 & 6693 \\
\hline 1979 & 7947 & 7690 & 8844 \\
\hline 1980 & 10831 & 9549 & 8929 \\
\hline 1980 & 7402 & 6067 & 8160 \\
\hline 1981 & 8972 & 8139 & 8789 \\
\hline 1982 & 7658 & 6569 & 8826 \\
\hline 1983 & 8533 & 9057 & 9324 \\
\hline 1984 & 7851 & 5810 & 11023 \\
\hline 1985 & 7947 & 5127 & 9265 \\
\hline 1986 & 8606 & 6665 & 6729 \\
\hline 1987 & 6691 & 7648 & 5810 \\
\hline 1987 & 8240 & 7519 & 10034 \\
\hline 1988 & 9741 & 8395 & 7904 \\
\hline 1989 & 6775 & 7178 & 11096 \\
\hline 1989 & 12524 & 10305 & 11279 \\
\hline 1992 & 8004 & 7402 & 10158 \\
\hline 1993 & 7800 & 6601 & 10876 \\
\hline 1993 & 8679 & 5713 & 8057 \\
\hline 1993 & 7727 & 7324 & 9851 \\
\hline 1995 & 8862 & 6870 & 9668 \\
\hline 1995 & 9045 & 7349 & 9698 \\
\hline 1996 & 9581 & 9997 & 9698 \\
\hline 1997 & 10693 & 10049 & 8789 \\
\hline 1997 & 8826 & 7904 & 10510 \\
\hline 1998 & 7434 & 5896 & 7861 \\
\hline 1998 & 6225 & 5933 & 9082 \\
\hline 1999 & 6262 & 6614 & 6702 \\
\hline 1999 & 10144 & 9177 & 6628 \\
\hline 1999 & 8057 & 5255 & 10107 \\
\hline 2000 & 8876 & 7405 & 9570 \\
\hline 2001 & 6518 & 6750 & 9595 \\
\hline 2001 & 8716 & 7536 & 7580 \\
\hline 2002 & 7654 & 8057 & 9961 \\
\hline 2002 & 7654 & 7900 & 9961 \\
\hline 2004 & 7210 & 8267 & 10305 \\
\hline 2004 & 7210 & 6067 & 10305 \\
\hline 2004 & 7613 & 5981 & 7947 \\
\hline 2005 & 8166 & 6216 & 9901 \\
\hline 2005 & 8386 & 8620 & 8935 \\
\hline 2007 & 6505 & 6460 & 7544 \\
\hline 2007 & 9631 & 9485 & 10400 \\
\hline
\end{tabular}

System Research Laboratory (ESRL), Climate Diagnostics Center, United States, for providing the National Centers for Environmental Prediction (NCEP Reanalysis 2) data from www.esrl.noaa.gov/psd/data/ gridded/data.ncep.reanalysis $2 . h t m l$. We also acknowledge the anonymous reviewers for their critical comments.

\section{APPENDIX}

\section{Barotropic Instability Problem}

These are two ways of studying the development of disturbances: namely,
1) eigenvalue problem (Holton 2004) and

2) the initial-value problem (Kuo 1953; also see chapter 6 of Krishnamurti et al. 2013).

Here we have adopted the initial value problem from V. B. Rao (1968, unpublished thesis). The symbols/ notations representing various variables/parameters in the appendix are listed below (Table A1).

To estimate the energy exchange between the basic zonal current and a superimposed disturbance in a barotropic, nondivergent, and frictionless atmosphere, we use the barotropic vorticity equation in the form

$$
\frac{d}{d t}\left(f+v_{E}\right)=0
$$

where

$$
\frac{d}{d t}=\frac{\partial}{\partial t}+u \frac{\partial}{\partial x}+v \frac{\partial}{\partial y}
$$

here, $f=2 \Omega \sin (\phi)$ is the Coriolis force term, $\phi$ is latitude, $v_{E}=\nabla^{2} \psi$ is relative vorticity, $\psi$ is streamfunction, and $u$ and $v$ are the zonal and meridional components of the horizontal velocity vector, and can be expressed as

$$
u=\frac{-\partial \psi}{\partial y} \quad \text { and } \quad v=\frac{\partial \psi}{\partial x} .
$$

As can be understood, $x$ and $y$ are the coordinate axes taken positive toward east and north, respectively.

Linearization of (A1) yields

$$
\frac{\partial}{\partial t} \nabla^{2} \psi+U \frac{\partial}{\partial x} \nabla^{2} \psi+\frac{\partial \psi}{\partial x}\left(\beta-\frac{\partial^{2} U}{\partial y^{2}}\right)=0,
$$

where $U$ is the mean zonal current, $\psi$ is the streamfunction for the perturbation flow, and $\beta=d f / d y$ is the Rossby factor.

A typical solution for (A2) will be

$$
\psi=A(y, t) \sin (k x)+B(y, t) \cos (k x),
$$

where $k=2 \pi / L$ is the wavenumber and $L$ is the wavelength.

Substituting solution (A3) in (A2) and equating the coefficients of $\sin (k x)$ and $\cos (k x)$ terms, we get the following equations:

$$
\begin{aligned}
\frac{\partial^{2}}{\partial y^{2}}\left(\frac{\partial A}{\partial t}\right)-k^{2} \frac{\partial A}{\partial t}= & -U\left(k^{3} B-K \frac{\partial^{2} B}{\partial y^{2}}\right) \\
& +k B\left(\beta-\frac{\partial^{2} U}{\partial y^{2}}\right) \text { and } \\
\frac{\partial^{2}}{\partial y^{2}}\left(\frac{\partial B}{\partial t}\right)-k^{2} \frac{\partial B}{\partial t}= & U\left(k^{3} A-K \frac{\partial^{2} A}{\partial y^{2}}\right) \\
& -k A\left(\beta-\frac{\partial^{2} U}{\partial y^{2}}\right) .
\end{aligned}
$$


TABLE A1. A complete list of the symbols/notations representing various variables/parameters in the appendix.

\begin{tabular}{ll}
\hline \hline Symbol & \\
\hline$f$ & Coriolis parameter \\
$\phi$ & Latitude \\
$v_{E}=\nabla^{2} \psi$ & Relative vorticity \\
$\psi$ & Streamfunction for perturbation flow \\
$u$ & Zonal wind \\
$v$ & Meridional wind \\
$U$ & Mean zonal wind \\
$\beta=\frac{d f}{d y}$ & Rossby factor \\
$k=\frac{2 \pi}{L}$ & Wavenumber \\
$p$ & Pressure \\
$t$ & Time \\
$L$ & Wavelength \\
$D$ & Channel width \\
$Q$ & Any disturbance quantity \\
$A, B$ & Amplitude \\
$K_{r}$ & Perturabation kinetic energy \\
$K_{r_{z}}$ & Zonal kinetic energy \\
$R$ & Radius of Earth \\
$d x$ and $d y$ & Incremental zonal and meridional distances \\
$a, \alpha, c$ & $\quad$ used in integration/differentiation \\
$\Omega$ & Wavelength \\
$\omega$ & Vertical " $p$ " velocity \\
$\Delta$ & Angular speed of Earth \\
$\Delta^{2}$ & Del operator applied to a quantity that varies \\
\hline
\end{tabular}

Equations (A4) and (A5) are two unknown equations with two unknowns, $\partial A / \partial t$ and $\partial B / \partial t$, and so form a closed system of equations.

From the prescribed initial values of $u, A, B$, and $\partial^{2} U / \partial y^{2}$ and with proper boundary conditions, we can find solutions for $\partial A / \partial t$ and $\partial B / \partial t$.

\section{a. Initial conditions}

The initial conditions are given by

$$
A_{o}=0 \quad \text { and } \quad B_{o}=a \sin (l y), \quad l=\frac{\pi}{D},
$$

where $D$ is the channel width, and suffix $o$ represents the initial value. As pointed out by Platzman (1952), it is desirable to take initial conditions in such a way as to make the first derivative of perturbations kinetic energy zero. As will be shown later specifically in (A10), (A6) will fulfill the requirement.

\section{b. Boundary conditions-Meridional direction}

In the meridional direction the boundary conditions are

$$
\begin{aligned}
& A=0 \text { at } y=0 \quad \text { and } y=D ; \\
& \frac{\partial A}{\partial t}=0 \quad \text { and } \quad \frac{\partial B}{\partial t}=0 \text { at } y=0 \quad \text { and } \quad y=D .
\end{aligned}
$$

In the $x$ direction we assume that the disturbance quantities have cyclic periodicity at intervals of one wavelength $L$. If $Q$ is any disturbance quantity, then $Q(x, y)=Q(x \pm L, y)$. Thus it is sufficient to consider the domain of integration as the area bounded by one wavelength $L$ in the $x$ direction and distance $D$ in the $y$ direction to evaluate various kinds of energies.

\section{c. Time tendency of amplitudes}

Amplitudes $A$ and $B$ after a time $\Delta t$ are given by the Taylor's series

$$
\begin{aligned}
& A(\Delta t)=A_{o}+\left(\frac{\partial A}{\partial t}\right)_{o} \Delta t+\frac{1}{2}\left(\frac{\partial^{2} A}{\partial t^{2}}\right)_{0} \Delta t^{2} \pm \cdots \quad \text { and } \\
& B(\Delta t)=B_{o}+\left(\frac{\partial B}{\partial t}\right)_{o} \Delta t+\frac{1}{2}\left(\frac{\partial^{2} B}{\partial t^{2}}\right)_{0} \Delta t^{2} \pm \cdots
\end{aligned}
$$

If $\Delta t$ is sufficiently small, the above series can be truncated after the second derivative. This will no doubt introduce some error in the forecasted amplitudes. Nevertheless, it is not an essential shortcoming as shown by the results.

With initial conditions given in (A6), (A5) becomes

$$
\frac{\partial^{2}}{\partial y^{2}}\left(\frac{\partial B}{\partial t}\right)-k^{2}\left(\frac{\partial B}{\partial t}\right)=0 .
$$

It can easily be shown from (A10) and (A7) that $(\partial B / \partial t)_{o}=0$ everywhere.

Equations for $\left(\partial^{2} A / \partial t^{2}\right)_{0}$ and $\left(\partial^{2} B / \partial t^{2}\right)_{0}$ can be obtained by differentiating (A4) and (A5) with respect to time. They take the form

$$
\begin{aligned}
\frac{\partial^{2}}{\partial y^{2}}\left(\frac{\partial^{2} A}{\partial t^{2}}\right)-k^{2} \frac{\partial^{2} A}{\partial t^{2}}= & -U\left[k^{3} \frac{\partial B}{\partial t}-K \frac{\partial^{2}}{\partial y^{2}}\left(\frac{\partial B}{\partial t}\right)\right] \\
& +k \frac{\partial B}{\partial t}\left(\beta-\frac{\partial^{2} U}{\partial y^{2}}\right) \text { and } \\
\frac{\partial^{2}}{\partial y^{2}}\left(\frac{\partial^{2} B}{\partial t^{2}}\right)-k^{2} \frac{\partial^{2} B}{\partial t^{2}}= & U\left[k^{3} \frac{\partial A}{\partial t}-K \frac{\partial^{2}}{\partial y^{2}}\left(\frac{\partial A}{\partial t}\right)\right] \\
& -k \frac{\partial A}{\partial t}\left(\beta-\frac{\partial^{2} U}{\partial y^{2}}\right) .
\end{aligned}
$$

Initial conditions in (A6) are used to obtain (A11) and (A12) since $(\partial B / \partial t)_{o}=0$ from (A11) and (A7) it can easily be shown that $\left(\partial^{2} A / \partial t^{2}\right)_{0}=0$ everywhere, so (A8) and (A9) reduce to

$$
\begin{aligned}
& A(\Delta t)=\left(\frac{\partial A}{\partial t}\right)_{o} \Delta t \text { and } \\
& B(\Delta t)=B_{o}+\frac{1}{2}\left(\frac{\partial^{2} B}{\partial t^{2}}\right)_{o} \Delta t^{2},
\end{aligned}
$$


so after time $\Delta t, \psi$ is given by

$$
\begin{aligned}
\psi(\Delta t) & =A(\Delta t) \sin (k x)+B(\Delta t) \cos (k x) \quad \text { and } \\
\psi(\Delta t) & =R_{\psi} \cos (k x-\delta \psi), \text { where } \\
R_{\psi} & =\left[A^{2}(\Delta t)+B^{2}(\Delta t)\right]^{1 / 2} \text { and } \tan (\delta \psi)=\frac{A(\Delta t)}{B(\Delta t)} .
\end{aligned}
$$

Thus, the amplitude and phase of $\psi$ wave can be found after time $\Delta t$ from (A15).

\section{d. Initial change of kinetic energy}

The rate of change of kinetic energy may be regarded as the rate of amplification of the disturbances. If it is positive, kinetic energy tends to increase with time, and disturbance is said to be unstable. If it is negative, kinetic energy tends to decrease, and the disturbance is said to be stable or damping. If the rate of change of kinetic energy is zero, the kinetic energy remains constant, and the disturbance is said to be neutral.

The kinetic energy of the disturbance is given by

$$
K_{r}=\int_{0}^{D} \int_{0}^{L} \frac{u^{2}+v^{2}}{2} d x d y
$$

but

$$
\begin{aligned}
& u=\frac{-\partial \psi}{\partial y}=-\left[\frac{\partial A}{\partial y} \sin (k x)+\frac{\partial B}{\partial y} \cos (k x)\right] \text { and } \\
& v=\frac{\partial \psi}{\partial x}=-k[A \cos (k x)-B \sin (k x)] .
\end{aligned}
$$

Inserting (A17) and (A18) into (A16), we get

$$
K_{r}=\frac{\pi}{2 k} \int_{0}^{D}\left[\left(\frac{\partial A}{\partial y}\right)^{2}+\left(\frac{\partial B}{\partial y}\right)^{2}+k^{2}\left(A^{2}+B^{2}\right)\right] d y .
$$

Differentiating (A19) with respect to time and using (A4), (A5), and (A7), we get

$$
\frac{\partial K_{r}}{\partial t}=-\pi \int_{0}^{D} U\left(A \frac{\partial^{2} B}{\partial y^{2}}-B \frac{\partial^{2} A}{\partial y^{2}}\right) d y .
$$

The equation for the time change of the zonal wind is

$$
\frac{\partial U}{\partial t}=-\frac{\partial}{\partial y} \overline{u v}
$$

where the overbar denotes a zonal average.

Multiplying (A21) by $U$ and integrating over the region we get the equation for the time change of zonal kinetic energy as

$$
\frac{\partial}{\partial t} K_{r_{z}}=-\int_{0}^{D} \int_{0}^{L} U \frac{\partial}{\partial y} \overline{u v} d x d y
$$

where $K_{r_{z}}$ is the zonal kinetic energy given by

$$
K_{r_{z}}=-\int_{0}^{D} \int_{0}^{L}\left(\frac{U^{2}}{2}\right) d x d y .
$$

Using (A17) and (A18),

$$
\overline{u v}=\frac{k}{2}\left(B \frac{\partial A}{\partial y}-A \frac{\partial B}{\partial y}\right) .
$$

Using (A23) and (A22) becomes

$$
\frac{\partial}{\partial t} K_{r_{z}}=\pi \int_{0}^{D} U\left(A \frac{\partial^{2} B}{\partial y^{2}}-B \frac{\partial^{2} A}{\partial y^{2}}\right) d y .
$$

It is seen from (A20) and (A24) that the right-hand side of (A24) is the same as the right-hand side of (A20) but with opposite sign. Thus, this term represents the interaction between the zonal and perturbation kinetic energies.

In view of our initial conditions,

$$
\left(\frac{\partial K_{r}}{\partial t}\right)_{0}=\left(\frac{\partial K_{r_{z}}}{\partial t}\right)_{0}=0
$$

Thus, as pointed out, earlier our initial conditions are such that the first derivative of perturbation kinetic energy is made equal to zero. So we have to consider the second derivative of perturbation kinetic energy $K_{r}$ in order to find out the initial change of kinetic energy, then

$$
\frac{\partial^{2}}{\partial t^{2}} K_{r_{z}}=-\pi \int_{0}^{D} U\left[\left(\frac{\partial A}{\partial t}\right)_{o} \frac{\partial^{2} B_{o}}{\partial y^{2}}-B_{o} \frac{\partial^{2}}{\partial y^{2}}\left(\frac{\partial A}{\partial t}\right)_{o}\right] d y .
$$

Initial conditions are used to get (A26).

Now, we will study the stability properties of different zonal currents with initial disturbance

$$
\begin{aligned}
\psi & =a \sin (l y) \cos (k x), \quad \text { that is, } \\
B_{o} & =a \sin (l y) \text { and } A_{o}=0 .
\end{aligned}
$$

The actual forms of the zonal current will be selected in such a way as to study different aspects of the problem.

The zonal current $U$ is given by

$$
U=c \cos (2 l y), \text { where } \quad l=\frac{\pi}{D} .
$$

We shall discuss this symmetric mean zonal current. This profile has two inflections points (where $\partial^{2} u / \partial y^{2}=0$ ) 
midway between the axis of the flow and the walls. Kuo (1949) found that the presence of flex points plays an important role in the barotropic stability problem.

We now need to solve (A4) for the above-prescribed zonal wind profile and $B_{o}$ [given by (A27)]. Here, $\beta$ is given as

$$
\beta=\frac{2 \Omega \cos (\phi)}{R}=\frac{\Omega}{R}[1+\cos (2 \phi)]^{1 / 2}=\frac{\Omega}{R}[1+\alpha \cos (l y)],
$$

where $R$ is the radius of Earth and $\alpha<1$.

With the prescribed expressions for $U, B$, and $\beta$, (A4) is solved with the boundary conditions in (A7) to give

$$
\begin{aligned}
\left(\frac{\partial A}{\partial t}\right)_{o}= & -\frac{E}{k^{2}+l^{2}} \sin (l y)-\frac{F}{k^{2}+4 l^{2}} \sin (2 l y) \\
& -\frac{G}{k^{2}+9 l^{2}} \sin (3 l y)-\cdots,
\end{aligned}
$$

where

$$
\begin{aligned}
E & =\frac{k a \Omega}{R}+\frac{k^{3} a c}{2}-\frac{3 \mathrm{k} a c l^{2}}{2}, \\
F & =\frac{k a \Omega \alpha}{2 R}, \text { and } \\
G & =\frac{3}{2} l^{2} k a c-\frac{k^{3} a c}{2} .
\end{aligned}
$$

With the expressions for $(\partial A / \partial t)_{o}, B_{o}$, and $U$, the integral in (A26) is evaluated to give

$$
\begin{gathered}
\left(\frac{\partial^{2} K_{r}}{\partial t^{2}}\right)_{o}=\frac{k a^{2} c^{2} l^{2} \pi D}{k^{2}+9 l^{2}}\left(3 l^{2}-k^{2}\right) \quad \text { and } \\
\left(\frac{\partial^{2} K_{r}}{\partial t^{2}}\right)_{o}\left\{\begin{array}{lll}
=0 & \text { when } & L=\frac{2 D}{\sqrt{3}} \\
>0 & \text { when } & L>\frac{2 D}{\sqrt{3}} \\
<0 & \text { when } & L<\frac{2 D}{\sqrt{3}}
\end{array}\right.
\end{gathered}
$$

Thus, the neutral wavelength $L<2 D / \sqrt{3}$ separates the stable shorter waves and unstable longer waves. It is to be noted that the terms due to Earth's rotation will not appear in (A30). So Earth's rotation will not contribute to $\left(\partial^{2} K_{r} / \partial t^{2}\right)_{o}$ with the symmetric profile for $U$ considered. The value of $\left(\partial^{2} K_{r} / \partial t^{2}\right)_{o}$ is maximum at a wavelength $2.1 D$ and so is the most unstable disturbance.

\section{REFERENCES}

Aihara, M., 1959: Stability properties of large-scale baroclinic disturbances in a vertically and horizontally variable zonal current. J. Meteor. Soc. Japan, 37, 45-58.
Alexander, G., R. Keshavamurty, U. De, R. Chellapa, S. Das, and P. Pillai, 1978: Fluctuations of monsoon activity. Indian J. Meteor. Hydrol. Geophys., 29, 76-87.

Blanford, H. F., 1886: The Rainfall of India. Meteorological Department, Government of India, $668 \mathrm{pp}$.

Boos, W. R., J. V. Hurley, and V. S. Murthy, 2015: Adiabatic westward drift of Indian monsoon depressions. Quart. J. Roy. Meteor. Soc., 141, 1035-1048, doi:10.1002/qj.2454.

Chen, W., S. Yang, and R. H. Huang, 2005: Relationship between stationary planetary wave activity and the East Asian winter monsoon. J. Geophys. Res., 110, D14110, doi:10.1029/ 2004JD005669.

Choudhury, A., and R. Krishnan, 2011: Dynamical response of the south Asian monsoon trough to latent heating from stratiform and convective precipitation. J. Atmos. Sci., 68, 1347-1363, doi:10.1175/2011JAS3705.1.

Das, P. K., 2002: The Monsoons. National Book Trust of India, 254 pp.

Goswami, B. N., 2011: South Asian summer monsoon. Intraseasonal Variability in the Atmosphere-Ocean Climate System, 2nd ed. W. K.-M. Lau and D. E. Waliser, Eds., Springer, 21-72.

- , and R. S. Ajayamohan, 2001: Intraseasonal oscillations and interannual variability of the Indian summer monsoon. J. Climate, 14,1180-1198, doi:10.1175/1520-0442(2001)014<1180: IOAIVO $>2.0 . \mathrm{CO} ; 2$.

— R. N. Keshavamurthy, and V. Satyan, 1980: Role of barotropic, baroclinic and combined barotropic-baroclinic instability for the growth of monsoon depressions and mid-tropospheric cyclones. Proc. Indian Acad. Sci., Earth Planet. Sci., 89, 79-97, doi:10.1007/BF02841521.

- R. S. Ajayamohan, P. K. Xavier, and D. Sengupta, 2003: Clustering of low pressure systems during the Indian summer monsoon by intraseasonal oscillations. Geophys. Res. Lett., 30, 1431, doi:10.1029/2002GL016734.

Holton, J. R., 2004: An Introduction to Dynamic Meteorology. 4th ed. Academic Press, 535 pp.

India Meteorological Department, 2012: Tracks of cyclones and depressions over North Indian Ocean 1891-2015. India Meteorological Department, Regional Meteorological Centre, Chennai. [Available online at http://www.rmcchennaieatlas.tn.nic.in.]

Joseph, P. V., and S. Sijikumar, 2004: Intraseasonal variability of the low-level jet stream of the Asian summer monsoon. J. Climate, 17, 1449-1458, doi:10.1175/1520-0442(2004)017<1449: IVOTLJ $>2.0 . \mathrm{CO} ; 2$.

Joseph, S., A. K. Sahai, and B. N. Goswami, 2009: Eastward propagating MJO during boreal summer and Indian monsoon droughts. Climate Dyn., 32, 1139-1153, doi:10.1007/s00382-008-0412-8.

Kanamitsu, M., W. Ebisuzaki, J. Woollen, S.-K. Yang, J. J. Hnilo, M. Fiorino, and G. L. Potter, 2002: NCEP-DOE AMIP-II Reanalysis (R-2). Bull. Amer. Meteor. Soc., 83, 1631-1643, doi:10.1175/BAMS-83-11-1631.

Krishnamurthy, V., and J. Shukla, 2007: Intraseasonal and seasonally persisting patterns of Indian monsoon rainfall. J. Climate, 20, 3-20, doi:10.1175/JCLI3981.1.

_ , and R. S. Ajayamohan, 2010: Composite structure of monsoon low pressure systems and its relation to Indian rainfall. J. Climate, 23, 4285-4305, doi:10.1175/2010JCLI2953.1.

Krishnamurti, T. N., and P. Ardanuy, 1980: The 10 to 20-day westward propagating mode and "breaks in the monsoons." Tellus, 32, 15-26, doi:10.1111/j.2153-3490.1980.tb01717.x.

, and D. Subrahmanyam, 1982: The 30-50 day mode at $850 \mathrm{mb}$ during MONEX. J. Atmos. Sci., 39, 2088-2095, doi:10.1175/ 1520-0469(1982)039<2088:TDMAMD>2.0.CO;2. 
—_, L. Stefanova, and V. Misra, 2013: Tropical Meteorology: An Introduction. 4th ed. Springer, 423 pp., doi:10.1007/ 978-1-4614-7409-8.

Krishnan, R., C. Zhang, and M. Sugi, 2000: Dynamics of breaks in the Indian summer monsoon. J. Atmos. Sci., 57, 1354-1372, doi:10.1175/1520-0469(2000)057<1354:DOBITI >2.0.CO;2.

_-, V. Kumar, M. Sugi, and J. Yoshimura, 2009: Internal feedbacks from monsoon-midlatitude interactions during droughts in the Indian summer monsoon. J. Atmos. Sci., 66, 553-578, doi:10.1175/2008JAS2723.1.

Kuo, H.-L., 1949: Dynamic instability of two-dimensional nondivergent flow in barotropic atmosphere. J. Meteor., 6, 105-122, doi:10.1175/1520-0469(1949)006<0105:DIOTDN >2.0.CO;2.

_ - 1951: Dynamical aspects of the general circulation and the stability of zonal flow. Tellus, $\mathbf{3}, 268-284$, doi:10.1111/ j.2153-3490.1951.tb00809.x.

- 1953: On the production of mean zonal currents in the atmosphere by large scale disturbances. Tellus, 5, 475-493, doi:10.3402/tellusa.v5i4.8695.

Mitra, A. K., M. Das Gupta, S. V. Singh, and T. N. Krishnamurti, 2003a: Daily rainfall for the Indian monsoon region from merged satellite and rain gauge values: Large-scale analysis from real-time data. J. Hydrometeor., 4, 769-781, doi:10.1175/ 1525-7541(2003)004<0769:DRFTIM >2.0.CO;2.

— — - R. K. Paliwal, and S. V. Singh, 2003b: Observed daily large-scale rainfall patterns during BOBMEX-1999. Proc. Indian Acad. Sci., Earth Planet. Sci., 112, 223-232.

_ - A. K. Bohra, M. N. Rajeevan, and T. N. Krishnamurti, 2009: Daily Indian precipitation analysis formed from a merge of rain-gauge data with the TRMM TMPA satellite-derived rainfall estimates. J. Meteor. Soc. Japan, 87A, 265-279, doi:10.2151/jmsj.87A.265.

__ and Coauthors, 2013: Prediction of monsoon using a seamless coupled modelling system. Curr. Sci., 104, 1173-1182.

Pai, D. S., J. Bhate, O. P. Sreejith, and H. R. Hatwar, 2009: Impact of MJO on the intraseasonal variation of summer monsoon rainfall over India. Climate Dyn., 36, 41-55, doi:10.1007/ s00382-009-0634-4.

Platzman, G. W., 1952: The increase or decrease of mean flow energy in large-scale horizontal flow in the atmosphere. J. Meteor., 9, 347-358, doi:10.1175/1520-0469(1952)009<0347: TIODOM $>2.0 . \mathrm{CO} ; 2$.

Raghavan, K., 1973: Tibetan anticyclone and tropical easterly jet. Pure Appl. Geophys., 110, 2130-2142, doi:10.1007/ BF00876576.

Rajeevan, M., J. Bhate, J. D. Kale, and B. Lal, 2006: High resolution daily gridded rainfall data for the Indian region: Analysis of break and active monsoon spells. Curr. Sci., 91, 296-306.

_ - S. Gadgil, and J. Bhate, 2008: Active and break spells of Indian summer monsoon. National Climate Centre Research Rep. 7/2008, India Meteorological Department, 44 pp.
,-- , and - 2010: Active and break spells of the Indian summer monsoon. J. Earth Syst. Sci., 119, 229-248, doi:10.1007/s12040-010-0019-4.

Ramamurthy, K., 1969: Monsoon of India: Some aspects of the "break" in the Indian southwest monsoon during July and August. India Meteorological Department Forecasting Manual Part IV, 18.3, 57 pp. [Available online at http://www.imdpune. gov.in/Weather/Forecasting_Mannuals/IMD_IV-18.3.pdf.]

Raman, C. R. V., and Y. P. Rao, 1981: Blocking highs over Asia and monsoon droughts over India. Nature, 289, 271-273, doi:10.1038/ $289271 \mathrm{a} 0$.

Ramaswamy, C., 1956: The Indian southwest monsoon. Seminar in the International Meteorological Institute, Stockholm, Sweden. 1962: Breaks in the Indian summer monsoon as a phenomenon of interaction between the easterly and the subtropical westerly jet streams. Tellus, 14, 337-349, doi:10.3402/ tellusa.v14i3.9560.

Rao, V. B., 1971: Dynamic instability of the zonal current during a break monsoon. Tellus, 23, 111-112, doi:10.1111/ j.2153-3490.1971.tb00552.x.

Rao, Y. P., 1976: Southwest Monsoon. Meteor. Monogr., No. 1/1976, India Meteorological Department, $366 \mathrm{pp}$.

Satyan, V., R. N. Keshavamurthy, B. N. Goswami, S. K. Dash, and H. S. S. Sinha, 1980: Monsoon cyclogenesis and large-scale flow patterns over South Asia. Proc. Indian Acad. Sci., Earth Planet. Sci., 89A, 277-292.

Shukla, J., 1977: Barotropic-baroclinic instability of mean zonal wind during summer monsoon. Pure Appl. Geophys., 115, 1449-1461, doi:10.1007/BF00874418.

1978: CISK-barotropic-baroclinic instability and the growth of monsoon depressions. J. Atmos. Sci., 35, 495-508, doi:10.1175/1520-0469(1978)035<0495:CBBIAT >2.0.CO;2.

Sikka, D. R., and C. M. Dixit, 1972: A study of satellite observed cloudiness over the equatorial Indian Ocean and India during the Southwest monsoon season. J. Mar. Biol. Assoc. India, 14, 805-818.

_ , and S. Gadgil, 1980: On the maximum cloud zone and the ITCZ over Indian longitude during the southwest monsoon. Mon. Wea. Rev., 108, 1840-1853, doi:10.1175/1520-0493(1980)108<1840: OTMCZA $>2.0 . C O ; 2$.

and R. Narsimha, 1995: Genesis of the monsoon trough boundary layer experiment (MONTBLEX). Proc. Indian Acad. Sci., Earth Planet. Sci., 104, 157-187, doi:10.1007/ BF02839270.

Starr, V. P., and R. M. White, 1954: Balance requirement of the general circulation. Geophysical Research Papers, Vol. 35, Geophysical Research Directorate, Air Force Cambridge Research Center, 57 pp.

Syōno, S., and M. Aihara, 1957: Some characteristic features of barotropic disturbances (II). J. Meteor. Soc. Japan, 35, 56-64.

Waliser, D. E., 2006: Intraseasonal variability. The Asian Monsoon, B. Wang, Ed., Springer, 203-258. 